\title{
A holistic vision of the influence of quality in the industrial process
}

\author{
Fernando Paulo Teles', Jandecy Cabral Leite ${ }^{1,2,}$, Lina Botelho ${ }^{1,2}$
}

\begin{abstract}
${ }^{1,2}$ Programa de Pós-Graduação em Engenharia de Processos do Instituto de Tecnologia da Universidade Federal do Pará (PPGEP-ITECUFPA). Avenida Augusto Correa No 01. Guamá. Belém-Pará-Brasil. CEP: 66075-110. Caixa Postal 479. PABX: +55 91 $3201-7000$.

${ }^{2}$ Instituto de Tecnologia e Educação Galileo da Amazônia (ITEGAM). Avenida Joaquim Nabuco No 1950. Centro. Manaus - Amazonas - Brasil. CEP: 60020-031. Fone: +55 9235846145.
\end{abstract}

Email: fpaulo.teles@gmail.com,jandecy.cabral@itegam.org.br

Received: January $23^{\text {th }}, 2017$

Accepted: February $17^{\text {th }}, 2017$

Published: March 30th 2017

Copyright $(2016$ by authors and Institute of Technology Galileo of Amazon (ITEGAM). This work is licensed under the Creative Commons Attribution International License (CC BY 4.0)

http://creativecommons.org/licenses/by/4.0/ (c) (1) (2)(2) Open Aecest

\begin{abstract}
This paper presents a holistic view of the influence of quality on industrial processes. In an increasingly competitive market, companies are looking for strategic decisions that guarantee their survival, thus making a holistic analysis of the current and future scenario, since quality has become a prime factor for organizational growth, as well as a Competitiveness mechanism. The objective of the study was to bring the influence that the quality makes in the industrial processes from the changes, until the adequacy for the total satisfaction of the client. The applied methodology was the one of bibliographical survey, in articles, books, dissertations, theses and monographs. The results show that quality is seen by companies as a key element for organizational development. In a holistic view, companies have focused on the concepts of quality, treating as a mechanism that has led to changes in production processes, being considered one of the responsible for customer satisfaction.
\end{abstract}

Keywords: Quality. Processes. Influence. Satisfaction.

\section{Uma visão holística da influência da qualidade no processo industrial}

\section{RESUMO}

Este artigo apresenta uma visão holística da influência da qualidade nos processos industriais. Em um mercado cada vez mais competitivo, as empresas buscam decisões estratégicas que garantem sua sobrevivência, fazendo assim, uma análise holística do cenário atual e futuro, haja vista que, a qualidade se tornou um fator primordial para o crescimento organizacional, além de, um mecanismo de competitividade. O objetivo do estudo foi trazer a influência que a qualidade faz nos processos industrial desde as mudanças, até a adequação para a satisfação total do cliente. A metodologia aplicada foi a de levantamento bibliográfico, em artigos, livros, dissertações, teses e monografias. Os resultados mostram que a qualidade é vista pelas empresas como um elemento chave para o desenvolvimento organizacional. Em uma visão holística, as empresas têm se direcionado para os conceitos de qualidade, tratando como um mecanismo que tem levado a mudanças nos processos de produção, por ser considerado um dos responsáveis pela satisfação do cliente.

Palavras-chave: Qualidade. Processos. Influência. Satisfação.

\section{INTRODUÇÃO}

O conceito de qualidade foi propagado a partir dos anos 50, seus princípios passaram a ser absorvidos pela maior parte das empresas. Começando a ser entendida como mecanismo estratégico, passando a ser valorizado pelo mercado, hoje, um fator de competitividade [1]. A partir da década de 80, o elemento qualidade se manifesta em nível mundial como uma ferramenta estratégia na luta pelos mercados consumidores, mudando a forma de tratar os processos produtivos, levando assim, as empresas à busca de controles eficazes, procurando dessa forma reduzir custos e por consequência maximizar os seus lucros [2]. 
A pesquisa apresenta um estudo numa visão holística da influência da qualidade nos processos industriais. Tendo em vista que, um dos princípios básicos da qualidade são a prevenção e a melhoria permanente. Considerando-se que, a qualidade é um planejamento constante, tornou-se as palavras-chaves mais difundidas junto às empresas e à sociedade. Haja vista que, para muitos que a qualidade está integrada a características intrínsecas de um bem, como desempenho e durabilidade. Já para outros, qualidade está associada à satisfação dos usuários, com relação à sua utilização.

Sendo que, a qualidade é do tamanho da satisfação dos clientes, com relação ao atendimento das suas necessidades [3]. Em decorrência da competitividade crescente entre as empresas, a qualidade passa a ser um fator de sucesso empresarial. Iniciando um trato com o ambiente tanto interno quanto externo, com a troca de experiências diversas, na tentativa de fazer melhor, com menos tempo e menos custo. A qualidade influencia os processos industriais, causando-lhes mudanças constantes [4].

É através do processo produtivo, que surgem todos os esforços e ações envolvidas para atender plenamente ao anseio do cliente. No processo de produção industrial a qualidade visa num primeiro momento eliminar perdas e as suas causas, além da otimização dos custos.

Trazendo os aspectos da qualidade que influência os processos produtivos, destacando que, as empresas precisam estar atentas às inovações tecnológicas inerentes ao seu processo industrial, e à modernização de seus equipamentos [5]. A influência da qualidade nos processos produtivos resulta em inovações de produto por meios tecnológicos. Já os novos processos são inovações para as produções em andamento, devendo-se frisar que, as organizações normalmente não influenciam diretamente nos processos de inovação, entretanto, a qualidade sim, por ser uma exigência do cliente [6].

A inovação constitui uma autêntica política empresarial, que define propósitos e perspectivas para o crescimento das empresas [7]. A qualidade converte-se em estratégia que direciona a empresa a atender bem os seus clientes, organizando de forma que venha garantir aos produtos e serviços característicos perceptivos pelos clientes, adequando-se as suas necessidades [8].

A pesquisa tem como objetivo trazer uma visão holística da inflência da qualidade nos processos industriais. Visto posto que, a qualidade é uma ferramenta muito importância para a competitividade e permanencia das empresas no mercado consumidor, torna-se relevante estudos holísticos que apontam a atuação da qualidade nos desenvolvimentos dos processos produtivos. A escolha deste de estudo, foi decorrente de que as empresas industriais estão sempre adequando os seus processos para permanência no mercado consumidor. Diante do exposto, surgiu a seguinte problemática: De que forma a Qualidade influência nos processos industriais?

\section{METODOLOGIA}

Trata-se de um estudo bibliográfico de natureza qualitativa, que eleva algumas técnicas que coadjuvam a descoberta de acontecimentos subentendidos, que reúnem um conjunto qualitativo de informações.

Durante a pesquisa qualitativa as técnicas não se pautou em um modelo único, exclusivo e padronizado. Segundo [9] "possibilitar a criação que mobiliza a acuidade inventiva do pesquisador, sua habilidade artesanal e perspicácia para elaborar a metodologia adequada ao campo da pesquisa, ao problema eleito"

$\mathrm{O}$ estudo bibliográfico compreende a leitura, análise e interpretação de conteúdos de livros, periódicos, textos legais, documentos mimeografados ou xerocopiados, mapas, fotos, manuscritos etc. Em uma análise atenta e sistemática que se faz acompanhar de anotações. Com o objetivo é levar ao conhecimento das diversas contribuições científicas disponíveis sobre determinado tema, além de proporcionar subsídios para a evolução das análises críticas [10].

O universo da produção bibliográfica que compôs o estudo compreende as publicações de artigos científicos veiculados nos periódicos e anais nacionais, Qualis A e B da Capes, da área das diversas áreas, no período de 1990 a 2015. Tendo em vista os propósitos do estudo, optou-se pela seleção dos periódicos da área da Qualidade. O processo de seleção dos periódicos apurou-se 14 periódicos, 10 Livros, 1 Simpósio e uma conferência na área da Qualidade. O processo de seleção dos artigos Uma vez definidas as fontes de coleta de dados, procedeu-se o processo da recolha dos artigos científicos.

Esta atividade foi alcançada através da pesquisa documental [11]. Este tipo de análise admite um entendimento de ocorrências específicas, conceituar com base em diversas visões e contrasta com métodos que se propõem a testar hipóteses. A pesquisa documental parte de uma visão de fora, em que o pesquisador se distancia da realidade pesquisada e utiliza instrumentos estruturados em conceitos teóricos para apurar objetivos específicos do seu estudo.

O instrumento estruturado da análise são artigos científicos e livros. De acordo com a [12] ABNT.NBR 6022 (2003, p.2)" artigo científico é parte de uma publicação com autoria declarada, que apresenta e discute ideias, métodos, técnicas, processos e resultados nas diversas áreas do conhecimento".

O processo de identificação dos artigos que compuseram a produção bibliográfica iniciou-se pela organização dos periódicos e anais dentro do ano de sua publicação. A partir desta dimensão, seguiram-se as seguintes fases de filtragem: Seleção, por discernimento, dos artigos que abordassem o indivíduo em contexto de trabalho; Definição das palavras-chaves que deveriam estar indexadas nos elementos pré-textuais "título" ou "resumo"; Procedimentos da análise foi através da análise de conteúdo como técnica de análise da produção bibliográfica. O objetivo desta técnica, de acordo com [13] é entender de forma critica o sentido das manifestações (escritas ou orais), ocultas ou explícitas de um determinado tema.

\section{A QUALIDADE E SUA EVOLUÇÃO HISTÓRICA}

A qualidade tem sua evolução com o aparecimento do controle de qualidade, apoiado por Shewhart na Inglaterra no século XX na década de 30, mostrando-se uma grande arma de melhoria. A principal ferramenta utilizada por Shewhart nesse período foi a escala de análise de erros e desvios no desempenho do padrão preestabelecido para investigação causal.

Ainda no século XX, na década de 50, os EUA que lideravam a crescente industrialização, principalmente nas indústrias automobilísticas, os Doutores Edward Deming e Joseph Juran, acabaram agregando pontos positivos utilizando técnicas para melhoria da qualidade, que posterior se tornaram modelos na produção mundial. Os japoneses também contribuíram implementando elementos que direcionava as relações fornecedorempresa, clientes-empregados e de operacionalizar o envolvimento 
dos empregados na organização através de ferramentas tais como CCQ e outros [14].

A qualidade passou a ser aplicada nas empresas resultando na melhoria gradativa dos processos e dos produtos. As empresas japonesas passaram então a ser um padrão internacional, oferecendo produtos de alta qualidade e a preços mais baixos.

De acordo com o Manual da Qualidade [15] que a aplicação do modelo de gestão da qualidade foi iniciado no Japão nos anos 70 e depois difundido por todo o mundo, especialmente Estados Unidos e Europa. Foi no EUA e na Europa que se deu início aos princípios básicos da gestão da qualidade. Sendo que na Europa vieram os modelos de valorização do fornecedor-empresa, recebendo o nome de modelo defensivo ou do comprador e no EUA o estilo norte- americano de conduzir sempre deixando claro a importância do cliente, caracterizando-se como modelo agressivo ou do vendedor.

\section{QUALIDADE}

A preocupação com a qualidade dentro das empresas surgiu no século XX. Entretanto, os diversos mecanismos das quais as organizações se planejam, definem, obtêm, controlam e melhoram seus processos, tem sofrido amplos desenvolvimentos nos últimos anos, contrapondo as modificações políticas, económicas e sociais, tendo como fator responsável à qualidade [16].

O quesito Controle da Qualidade é o foco dos três estágios deste modelo.

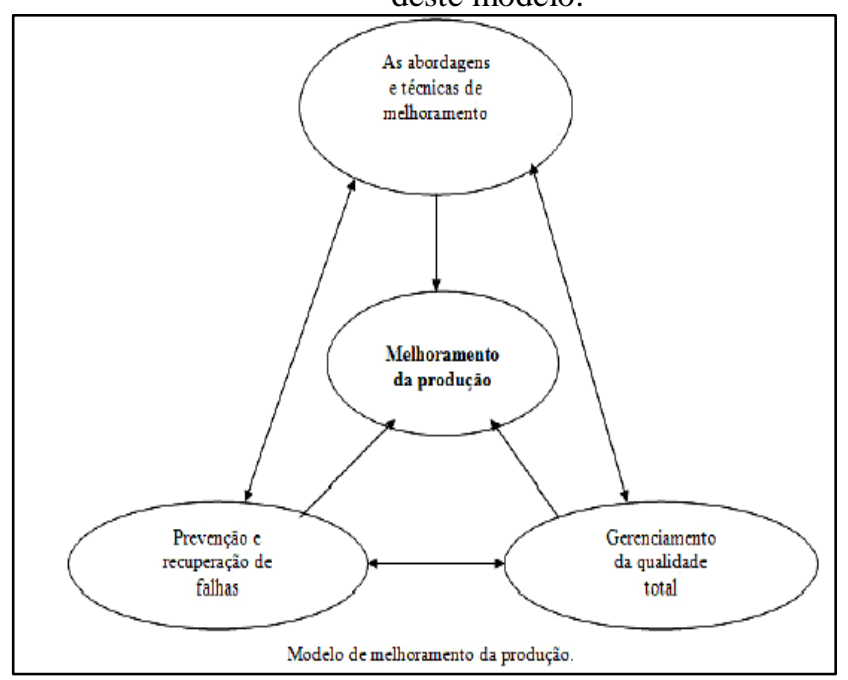

Figura 1: Modelo de melhoramento da produção.

Fonte: [17].

A qualidade é superior as coisas. A introdução da qualidade nas operações estratégicas das organizações acontece em uma totalidade que envolve principalmente mudanças cultural das pessoas que compõem a organização. Segundo o autor David A. [18], professor na Harvard Business School da Universidade de Harvard nos Estados Unidos, o desenvolvimento da qualidade divide-se em 4 etapas, as chamadas "Eras da Qualidade". A Qualidade, que tinha como foco apenas o produto acabado, em que se inspecionava o que era produzido, criando métodos para análise de amostras e inspeções, quer dizer, a estrutura de bom ou ruim. Procedimento este muito dispendioso e que não podiam sofrer alterações no que já havia sido feito.

\begin{tabular}{|lcccc}
\hline & \multicolumn{4}{c}{ Etapa do Movimento da Qualidade } \\
\cline { 2 - 5 } $\begin{array}{l}\text { Identificação das } \\
\text { Caracteristicas }\end{array}$ & Inspeção & $\begin{array}{c}\text { Controle Estatistico da } \\
\text { Qualidade }\end{array}$ & Garantia da Qualidade & $\begin{array}{c}\text { Gestão Estratégica da } \\
\text { Qualidade }\end{array}$ \\
\hline Enfase & uniformidade do produto & $\begin{array}{l}\text { uniformidade do produto } \\
\text { com menos inspeção }\end{array}$ & $\begin{array}{l}\text { toda a cadeia de produção, } \\
\text { desde o projeto até o necessidades do } \\
\text { mercado, e a contribuiçãa } \\
\text { de todos os grupos } \\
\text { funcionais }\end{array}$ & $\begin{array}{l}\text { mercado e do consumidor } \\
\text { Orientação e } \\
\text { abordagem }\end{array}$ \\
\hline
\end{tabular}

Figura 2: As Quatro Principais Eras da Qualidade. Fonte: [19].

As qualidades nos produtos passaram a ser praticadas nos processos de produção, originando assim, à Gestão da Qualidade, que direciona as atuações dos procedimentos para o completo atendimento do cliente [20].

A qualidade contribui com o alcance de três grandes objetivos organizacionais tais como: Abordagem sistemática de todas as atividades que envolvem o processo; Favorece as atividades de prevenção em todo processo; dá ênfase ao alcance dos resultados [21].

Na conjuntura empresarial, o fator qualidade, influência de forma direta a conformidade da produção de bens e/ou serviços dentro das especificações estabelecidas pelo projeto, é visto não só como uma exigência do consumidor, mas também como um fator de redução de custos, ou seja, quanto maior o número de produtos 
feitos de acordo com as especificações, menores serão os custos de perdas [22].

\section{VISÃO HOLÍSTICA}

A visão holística focaliza sempre entender em os acontecimentos em geral. O conceito Holístico foi mencionado por Jan Christiaan Smuts em 1926, que o descreveu como a disposição natural de usar o desenvolvimento criativo para compor um "todo" que é o máximo do que a soma das suas partes.

No campo empresarial, a visão holística é um contexto macro, de todos os seus elementos, estratégias e atividades, que resulta em uma representação única da organização, sendo o inverso da lógica mecanicista, que tem como ação de dividir os espaços em vários grupos, causando assim uma perda da visão total da organização [23].

A qualidade acarreta como influência a procura pela melhoria contínua, que se materializa na criação de um mecanismo de auto avaliação, podendo ser chamado de indicador de desempenho, que é capaz de avaliar a ciclos curtos, as atividades, e os resultados. Para ter-se um processo produtivo com eficiência deve-se focar na qualidade. O gestor tem o papel de se apresentar como diferenciador e facilitador de melhorias dando total importância para a comunicação, a mudança, a visão, o trabalho de equipe, a busca de resultados, a pró-atividade e o crescimento organizacional, sendo também responsável pelas mudanças nos processos.

A Qualidade não acaba com os problemas que podem chegar aos clientes, e nem tão pouco melhora parte de um processo. Qualidade não é meramente operacional, em que as inspeções sejam apenas nas linhas de fabricação, recebimento, produtos acabados, buscando a eliminação de falhas. Qualidade é um diferencial competitivo, que pode fazer com que uma organização permaneça ou não no mercado consumidor, proporcionando diminuição dos problemas, retrabalhos, além de aumentar a produção. Qualidade significa a mudança de um processo produtivo para a satisfação total do cliente [24].

\section{PROCESSOS PRODUTIVOS}

A existência dos processos produtivos foi em decorrência da produção de bens e serviços, tornando-se objetivo da existência das empresas. Os meios viáveis para o alcance de um dado objetivo em uma organização são através do resultado final, que envolve a satisfação dos clientes. Visto que, os processos produtivos têm suas atividades formadas por um conjunto de vários inputs de adição de valor e um output de saída [25].

Os processos de produção estão ligados de forma direta a produtos e/ou serviços que possuem um cliente final. Processo pode-se dizer que, é um conjunto de tarefas capazes de conduzir bens ou serviços, que envolve toda uma organização [26].

A produtividade nos processos produtivos se traduz no exercício da qualidade aplicada nas etapas de desenvolvimento, projeto, método fabril e venda de um produto, devendo ser atrativo na perspectiva econômico, com satisfação total do cliente e com redução de retrabalho e perdas, proporcionando uma maior competitividade [27].

Produção se entende como sendo toda e qualquer atividade relacionada à fabricação de produtos ou serviços, que a partir da transformação de insumos, matérias primas, recursos produtivos entre outros, agregam valor a cada etapa e ao produto final [28].

A produtividade dos processos produtivos só pode alcançar a excelência se for considera as informações disponibilizadas nos controles internos das empresas ou do benchmarking, para que possa realizar os controles e aplicar de forma correta as ferramentas da qualidade, gerando dados comparáveis nas dimensões de tempo e quantidade, de forma a produzir, dividindo em atividades com o menor custo possível, ajudando na tomada de decisão dos responsáveis envolvidos. Para [27] trabalha quatorze pontos, Quadro 1, que a qualidade influência no processo produtivo.

Quadro 1: Os Catorze Pontos de Deming.

\begin{tabular}{l|l}
\hline & \multicolumn{1}{c}{ Os catorze pontos de Deming } \\
\hline 1 & Estabelecer objetivos estáveis, com vista à melhoria dos produtos e serviços \\
\hline 2 & Adoptar a nova filosofia (de gestão da qualidade) \\
\hline 3 & Não depender exclusivamente da inspeção para aceitar a qualidade \\
\hline 4 & $\begin{array}{l}\text { Não utilizar apenas o preço para conduzir o negócio. Em vez disso, minimizar os custos totais trabalhando com um único } \\
\text { fornecedor }\end{array}$ \\
\hline 5 & $\begin{array}{l}\text { Melhorar constantemente os processos de planejamento, produção e fornecimento dos serviços trabalhando com um } \\
\text { único fornecedor }\end{array}$ \\
\hline 6 & Instituir a formação no posto de trabalho \\
\hline 7 & Adoptar e instruir a liderança da direção \\
\hline 8 & Eliminar o medo (de cometer erros) \\
\hline 9 & Eliminar barreiras funcionais entre áreas \\
\hline 10 & Eliminar slogans, anotações e cartazes dirigidos aos trabalhadores dos níveis mais baixos \\
\hline 11 & Eliminar indicadores monetários para os trabalhadores e numéricos para a gestão \\
\hline 12 & Eliminar as barreiras que dificultam o orgulho pelo trabalho realizado. Eliminar sistemas anuais, ou sistemas de mérito \\
\hline 13 & Instituir um sistema de formação e auto melhoria para toda a gente \\
\hline
\end{tabular}
Fonte: [27].

Observa-se no Quadro 1 que, os quatorzes pontos prescrito por Deming, mostra a grande influência da qualidade em todos os processos que envolvem a produção, além da mudança na cultura organizacional.
Vale enfatizar que, a qualidade só causa melhorias positiva se for aplicada corretamente. $\mathrm{O}$ uso inadequado das ferramentas da qualidade tende a causar mais prejuízos para o 
processo produtivo, por proporcionar resultados não reais dos problemas.

Sendo que, um processo que aparentemente está sobre controle, pode estar encobertando falhas que irão prejudicar os resultados da empresa mais à frente.

\section{A INFLUÊNCIA DA QUALIDADE NOS PROCESSOS PRODUTIVOS}

A medida que se define qualidade como a adaptação ao uso dos bens e/ ou serviços, analisando o ponto de vista dos clientes finais em cinco dimensões: qualidade intrínseca, custo, entrega, moral e segurança [29].

A influência da qualidade nos processos industriais, se propicia de amplos impactos dentro da organização buscando a excelência dos processos e não dos defeitos dos bens e serviços [30].

A qualidade em processos de produção é fundamentada para atender as especificações dos procedimentos, com a finalidade a não conformidade, procurando na cultura da empresa a disciplina, a persistência, foco na liderança e o investimento dos recursos humanos, além de toda uma restruturação organizacional, pois o custo que se gera nos processos, recai pela falta de qualidade [31].

A qualidade nos processos industriais pode ser percebida como a excelência no uso dos diversos recursos e meios disponíveis em uma empresa, obtendo assim produtos que satisfação a expectativas do cliente. Observa-se que a qualidade influência na mudança cultural da organização focalizando a contínua melhoria dos produtos e os processos.

Deming enfatiza que os padrões de qualidade de uma organização devem ser representar uma das preocupações mais relevantes, acima da capacidade produtiva, já que a qualidade deve ser vista antes mesmo de iniciar a produção [32].

Uma vez que a qualidade preventiva traz adicionados diversos benefícios, como diminuição de custos, redução de retrabalho e falhas, além de um melhor aproveitamento do tempo e dos materiais. Possibilitando que as empresas possam ter mais força para alcançar a liderança de mercado, ou manter-se sempre competitiva conforme mostra a figura 3 .

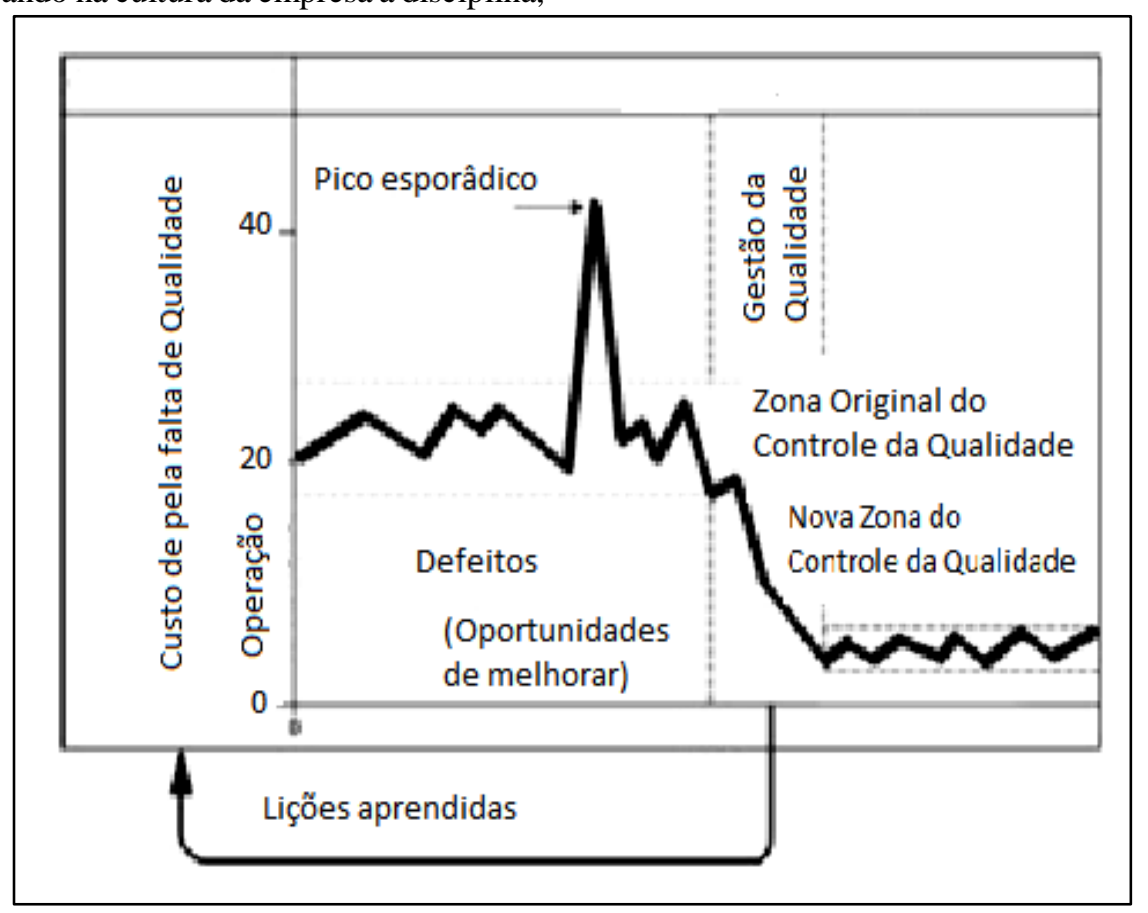

Figura 3: Qualidade nos processos.

Fonte: [33].

A qualidade é uma das maiores preocupações nas organizações, por ser considerada a chave do sucesso. Sua influência tem levado as instituições a fazerem mudanças até na sua estrutura organizacional. De forma que, vem gerando bens e serviços de alta qualidade [34].

Além de que, aplicar as ferramentas da qualidade nos procedimentos, traz uma redução de valores nos custos e aumento da lucratividade, e diminuição de defeitos e o mais importante, gera produtos e/ou serviços com alta qualidade, gerando um resultado final de clientes satisfeitos. As organizações confiam que, em longo prazo, a qualidade é considerada o fator essencial, que se não for levado a sério pode afetar o desempenho de uma empresa e baixa competividade.
Vale salientar que a qualidade reduz os custos de produção. Quanto menor forem os erros em cada unidade de produção, menos tempo será necessário para a correção, afora material será descartado, menos produtos serão reprovados e, e como consequência a empresa deixará de ter mais gastos além do previsto.

Visto que a qualidade aumenta a credibilidade da organização, os custos crescentes não são a única implicação. A falta de qualidade dos produtos pode gerar dificuldades de importância da organização, causando perca de clientes. Sendo que a melhoria da qualidade reflete no lucro de organizacional, através da redução de custos e aumento da lucratividade. 
Visivelmente se percebe a influência da qualidade em toda a estrutura organizacional e que são fatores necessários para manter os clientes antigos e atrair novos clientes. Devendo ser utilizadas ferramentas e métodos da qualidade que venha definir os problemas e ocorrências de problemas, além de, proporcionar informações e dados, para empreender melhor as mudanças e melhorias nos processos e, finalmente, com o objetivo de alcançar resultados eficiente, gerando um ciclo de melhoria contínua [35].

A estratégia se deve basear na relação mutua desde o projeto do produto, passando pela fabricação, e a o produto final, sem esquecer da cadeia de suprimento, além do grau de influência que eles possam ter sobre sua satisfação [36].

Tudo isso, influência a empresa a buscar a excelência em seus produtos. Sendo que as organizações entram em um sistema constante de melhoria e em uma busca cada vez mais de ser a melhor, com isso, a qualidade torna-se um fator primordial.

A influência da qualidade nos processos de produção é tanto que tem levado cada vez mais empresas a seguir o modelo proposto pelas normas ISO 9001, através do SGQ. Conforme o exigido na norma, a organização deve determinar que produtos ou serviços estejam incluídos no âmbito do sistema, bem como todos os processos que lhes dão origem, substituindo a abordagem tradicional de processos por uma abordagem integrada [37].

Vale ressaltar que, a qualidade em todos os âmbitos do processo, interfere de forma significativa moldando as empresas para que possa se manter competitiva. Na Figura 4, pode-se perceber o desenvolvimento da qualidade e a influência nos processos de produção.

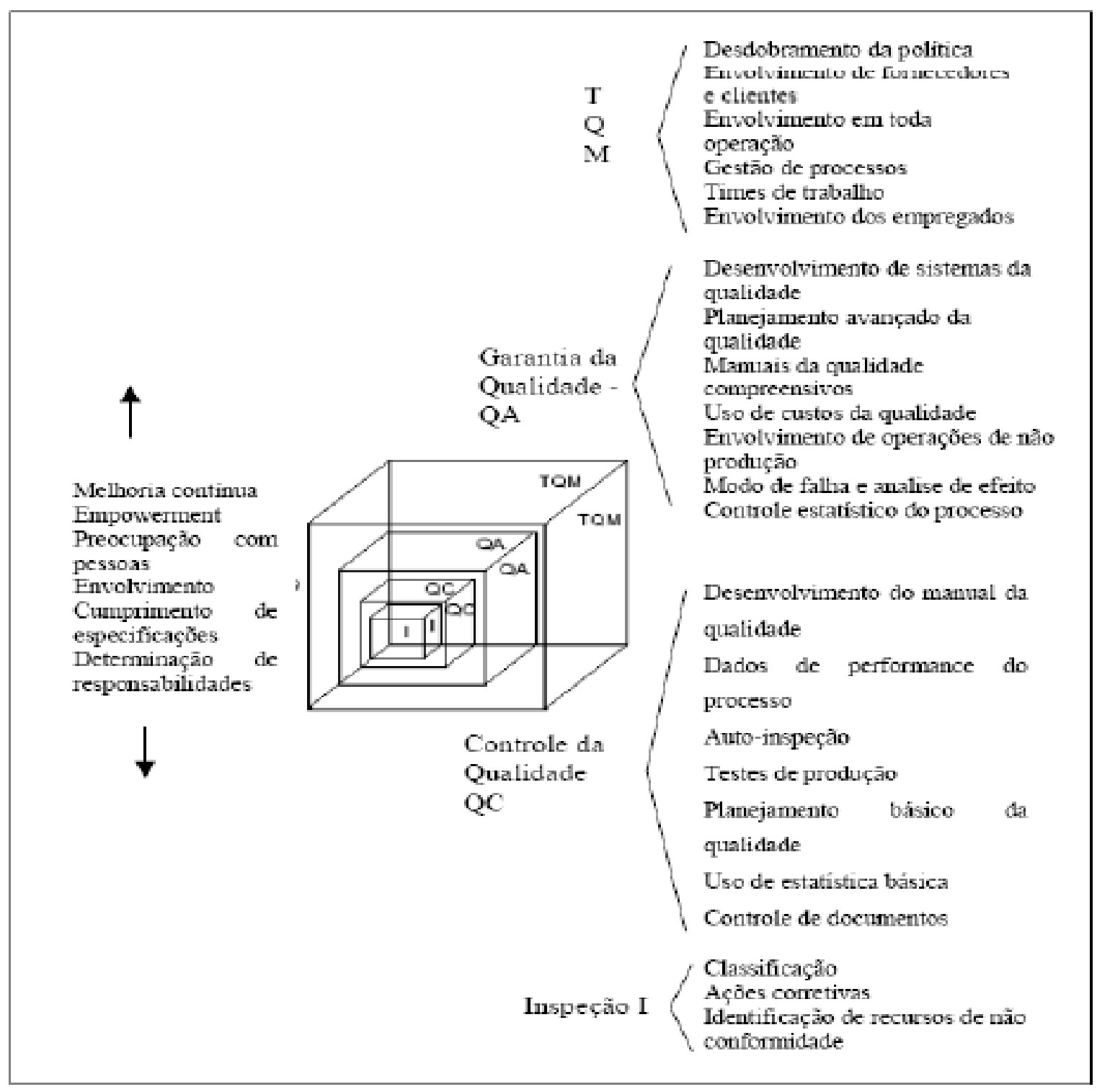

Figura 4: Quatro níveis em evolução da gestão da qualidade.

Fonte: [38]. 
Conforme se observa na Figura 5, dessa forma auxilia a comunicação entres os setores.

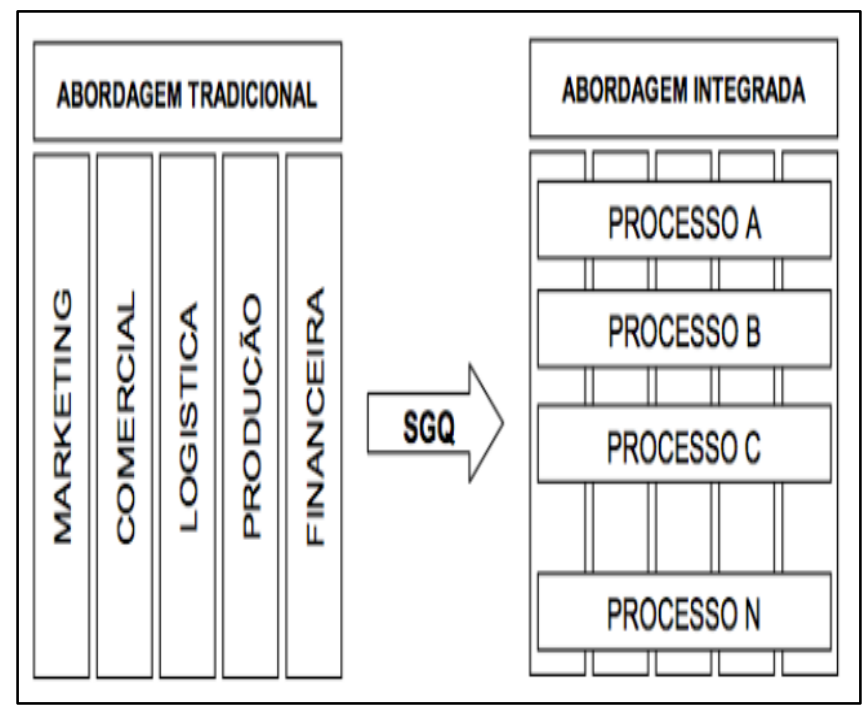

Figura 5: Substituição da Abordagem Tradicional pela Abordagem Integrada Fonte: [38].

No gerenciamento empresarial, as modificações acontecem em todos os processos, e surgem da necessidade das organizações seguirem as instabilidades incididas pela acirrada concorrência no mundo empresarial. Consequentemente, se o ambiente fosse estável, não seriam necessárias alterações nas operações e nas atividades dos negócios [30].

Por consequentemente, o ambiente interno e o ambiente externo constituem-se em variáveis permanentes que exercem influência sobre o desenvolvimento das organizações no decorrer do tempo.

Percebe-se o processo evolutivo, que indica a complementação de todos os estágios até chegar a Gestão da Qualidade Total - TQM, que engloba todas as contribuições das fases da qualidade. Fatores estes que tem tornado cada vez mais importante para o crescimento organizacional e competitivo. A qualidade torna-se um dos fatores que mais influência nas mudanças ocorridas nos processos de produção [39].

Decorrente das mudanças, ocorridas no cenário mundial, a qualidade influência diretamente os processos industriais os modificando, destacando que a lucratividade e os objetivos possam ser mantidos, mesmo em face de mudanças situacionais enfrentadas pelas organizações.

Neste ambiente, a criação de novos produtos e o desenvolvimento dos processos tornou-se um dos principais focos da organização e o fator de competitividade. Um dos conceitos da qualidade é a performance do produto, que oriunda da satisfação dos clientes com as características do produto, que o leva a comprálo. Podendo-se dizer que Qualidade é "adequação ao uso", mas existe várias formas de usá-los, sendo que todos estes são de alguma forma afetados pela qualidade dos produtos [33].

Para [37] esclarece dizendo que a qualidade é o elo que liga a empresa ao ambiente externo, fazendo com que ela se mantenha no mercado de forma estável e duradoura. A qualidade total é os mecanismos utilizados pelas empresas para corresponder aos anseios da sociedade consumidora. É necessário que a empresa estabeleça uma interação bem definida entre o que ela produz e o ambiente com o qual ela interage e que a qualidade deve ser gerada a partir do processo produtivo [40].

\section{CONSIDERAÇÕES FINAIS}

Com a oferta de um produto ou serviço a um custo compatível, tanto para organização como para o cliente com o Atendimento que gere satisfação do cliente.

Com a criação e manutenção de condições adequadas de trabalho, que permitam aos prestadores sentirem-se orgulhosos com as atividades que desempenham, com a segurança tanto para os clientes externos que recebem o produto ou serviço como para os funcionários da organização, com as regras de conduta e valores que norteiam as relações de trabalho.

A técnica utilizada neste estudo foi a de estudo bibliográfico, de forma que, a análise feita nos diversos conceitos de autores renomados, atendeu aos objetivos proposto. Mostrando que a qualidade influência os processos de produção diretamente, Em sumula, a influência que a qualidade exerce sobre os processos industriais deve ser entendida como uma nova maneira de ver as relações entre as pessoas, onde o benefício comum é superior ao de uma das partes e essa característica implica oferecer produtos e serviços em conformidade com os produtos e serviços nas especificações exigidas para o objetivo ao qual se destinam.

A utilização dos métodos da qualidade, gera um oferecimento de produtos e/ou serviços a um custo compatível, tanto para empresa quanto para o consumidor final, proporcionando um resultado final, que é medido pela satisfação do cliente. Para isso a empresa deve gerar condições adequadas de trabalho, ambiente favorável, uma estrutura adequada, um processo condizente com o produto a ser fabricado, com produtos acessíveis para os clientes alvos.

Portanto, a qualidade gera uma grande influência nas mudanças organizacionais, assim como, na melhoria dos produtos e serviços.

\section{REFERÊNCIAS}

[1] Marshall Junior, Isnard et al. Gestão da qualidade. 10. ed. Rio de Janeiro: Publicações FGV Management, FGV, 2010.

[2] Lakhal, L. Impact of quality on competitive advantage and organizational performance. The Journal of the Operational 
Research Society, 60(5), 637-645. 2009. Disponível em: <http://dx.doi.org/10.1057/ palgrave. jors.2602601>. Acesso em: 14 de jul. 2016.

[3] Gomes, P. J. A evolução do conceito de qualidade: dos bens manufaturados aos serviços de informação. Cadernos BAD. (2), pp. 618. 2004.

[4] Oliveira, Sidney dos Santos; Leite, Jandecy C.; Souza, José A. da S., Oliveira, Rosimeire Freires Pereira. Uso do Controle Estatístico de Processo (CEP) na gestão de operações produtivas em uma indústria no Polo Industrial de Manaus. Revista SODEBRAS. Volume $10 \mathrm{~N}^{\circ} 117$ de julho/2015.

[5] Las Casas, Alexandre Luzze. Qualidade Total e Serviços: Conceitos, exercícios, casos práticos. 6 ed. São Paulo: Atlas. 2008.

[6] Edquist, Charles, 2011. "Innovation Policy Design: Identification of Systemic Problems," Papers in Innovation Studies 2011/6, Lund University, CIRCLE - Center for Innovation, Research and Competences in the Learning Economy.

[7] Cunha, Maria dos Anjos Beirigo; Vasconcelos, Fernanda Carla Wasner. Inovação: Características das Indústrias de Confecção do Vestuário do Município de Divinópolis/Mg. Revista Sodebras Volume $9 \mathrm{~N}^{\circ} 103$ - Julho/ 2014.

[8] Moura, Luciano Raizer. Qualidade Simplesmente Total. Ed. Qualitymark Editora Ltda, Rio de Janeiro. 2003.

[9] Chizzotti, A. Pesquisa em ciências humanas e sociais. São Paulo: Cortez, 1991.

[10] GIL, A. C. Métodos e Técnicas de Pesquisa Social. São Paulo: Atlas, 2002.

[11] Roesch, Sylvia Maria Azevedo. Projetos de Estágio e de Pesquisa em Administração: Guia para Estágios, Trabalhos de Conclusão, Dissertações e Estudo de Caso. $3^{\mathrm{a}}$ Edição. São Paulo. Atlas, 2007.

[12] Associação Brasileira de Normas Técnicas (ABNT). Informação e documentação - Artigo em publicação periódica científica impressa - Apresentação. NBR 6022. Rio de Janeiro. RJ. Maio de 2003.

[13] Bardin, L. Análise de Conteúdo. Lisboa, Portugal; Edições 70, LDA, 2009.

[14] Podestá Junior, Arnaldo. Fatores motivacionais e a qualidade do trabalho dos servidores técnico-administrativos do Departamento de Materiais e Serviços Gerais da Universidade Federal de Santa Catarina - Dissertação (Mestrado) - Universidade

Federal de Santa Catarina, Centro Tecnológico, Programa de PósGraduação em Engenharia de Produção. Florianópolis, 2002.

[15] Fundação CERTI. Manual da qualidade, 1996.

[16] Mendes, M. F. (2007). O impacto dos sistemas QAS nas PME portuguesas. Dissertação de Mestrado. Universidade do
Minho, Minho, http://hdl.handle.net/1822/7967.

[17] SLACK, N.; CHAMBERS, S.; HARLAND, C.; HARRISON, A.\& JOHNSTON, R. Administração da Produção. Atlas. São Paulo. 1997.

[18] Garvin, D. A. (1988). Managing Quality. New York: The Free Press.

[19] Costa, A.F.B; Eprechet, E.K; Carpinetti, L.C.R. Controle estatístico da qualidade. São Paulo: Atlas. 2004.

[20] Zarpelon, Marcio Ivanor; Carvalho, Denise Maria Woranovicz. Informação de Qualidade: A Proposta do Modelo Infoqual. Revista Sodebras-Volume 8-N 89-Maio/ 2013.

[21] Pires, R. A. Sistemas de Gestão da Qualidade - Ambiente, Segurança, Responsabilidade Social, Indústria, Serviços, Administração Pública e Educação. Lisboa: Edições Sílabo. 2012.

[22] Mariani, Celso Antonio. Método PDCA e Ferramentas da qualidade no gerenciamento de processos industriais: Um estudo de caso. RAI- Revista de Administração. São Paulo. v. 2. n. 2. p. 110126. 2005.

[23] Berrinelli, LA. Waskievicz, J. Erdmann AL. Humanização do cuidado no ambiente hospitalar. Mundo Saúde. 2003. 27: 231-239.

[24] Filho, Manassés Costa. As ferramentas de qualidade no processo produtivo com enfoque no processo enxuto. Faculdade Pitágoras Curso de MBA em Gestão da Manutenção, Produção e Negócios do Instituto Superior de Tecnologia - ICAP. Conselheiro Lafaiete. 2011.

[25] Pyzdek, T.; Keller, P.A. The Sis Sigma Handbook. McGraw-Hill. 3rd Edition. 2009.

[26] Fillietaz, Jonatas Ferreira. Análise do processo produtivo utilizando ferramentas de gestão da qualidade para diminuição de custos com perdas e falhas. Escola Politécnica da Universidade de São Paulo. 2006.

[27] Deming, W. E. Qualidade: a revolução da administração. Ed Marques Saraiva. 1990.

[28] Evans, J. R.; Lindsay, W. M. Managing for Quality and Performance Excellence. Thomson Learning Inc. 8th Edition. 2010.

[29] Alsaleh, N. A. Application of quality tools by the Saudi food industry. The TQM Magazine. v. 19. n. 2. 2007. p. 150-161.

[30] Goulart, Luiz Eduardo Takenouchi; Bernegozzi, Robson Peres. O uso das ferramentas da qualidade na melhoria de processos produtivos. XVI international conference on industrial engineering and operations management challenges and maturity of production engineering: competitiveness of enterprises, working conditions, environment. São Carlos, SP, Brazil, 12 to 15 October/2010.

[31] Manivannan, S. Error Proofing Enhances Quality. Manufacturing Engineering. November, pp 99-104. 2006. 
[32] Silva, Luan Carlos Santos; Kovaleski, João Luiz Kovaleski; GAIA, Silvia. Gestão da qualidade do produto no processo de produção industrial: Um estudo de caso em uma indústria de bebidas. Revista de Engenharia e Tecnologia. V. 4. No. 1. Abr/2012.

[33] Juran, J.M. A qualidade desde o projeto. São Paulo: Pioneira. 2006.

[34] Digrocco, Jesner Ricardo. Ferramentas da Qualidade. Administradores, São Paulo. 19. nov. 2008. Disponível em: <http://www.administradores.com.br/comunidades

/ferramentas_da_qualidade/395/>. Acesso em: 10 jul. 2016.

[35] Brito, Juliana de Lima, Santos, Patrícia Corrêa; Neto, Raimundo Drumond; Paz, Aldevando Carvalho; Amorim, Claudio Roberto Gonçalves de. Ferramentas Da Qualidade nas Indústrias de Papel e Celulose da Bahia. Revista Sodebras - Volume $10 \mathrm{~N}^{\circ} 109$ Janeiro/2015.

[36] Campos, Sonia T. C. C; Claro, Fernando; Lindgren, Paulo Cesar Correa; Neto, Antônio Faria. Estratégia para Rever e Implementar Melhoria Contínua da Qualidade no Processo Produtivo. VIII Simpósio de Excelência em Gestão e Tecnologia-SEGET. 2011.

[37] Paladini, Edson Pacheco. Gestão da Qualidade: Teoria e Prática. $2^{a}$ ed., São Paulo: Atlas S.A. 2010.

[38] Silva, M. Â. Desenvolvimento e implementação de um Sistema de Gestão da Qualidade. Dissertação de Mestrado, Universidade de Aveiro, Aveiro, Portugal. 2009. Disponível em: <http://hdl.handle.net/10773/1715 >. Acesso em: 14 de jul. de 2016.

[39] Araújo, C.A.C. Sistemas de Controle Lean para Fluxos Puxados e Nivelados. São Paulo: Hominiss. 2007.

[40] Liker, J. K.; Meier, D. O modelo Toyota. Manual de Aplicação. Ed. Bookman. 2007. 